\title{
Secretome diversity and quantitative analysis of cellulolytic Aspergillus fumigatus Z5 in the presence of different carbon sources
}

\author{
Dongyang Liu, Juan Li, Shuang Zhao, Ruifu Zhang, Mengmeng Wang, Youzhi Miao, Yifei Shen and Qirong Shen*
}

\begin{abstract}
Background: Aspergillus fumigatus Z5 has a strong ability to decompose lignocellulose biomass, and its extracellular protein secretion has been reported in earlier studies employing traditional techniques. However, a comprehensive analysis of its secretion in the presence of different carbon sources is still lacking. The goal of this work was to identify, quantify and compare the secretome of A. fumigatus Z5 in the presence of different carbon sources to understand in more details the mechanisms of lignocellulose decomposition by Aspergillus fumigatus Z5.

Results: Cellulolytic A. fumigatus $Z 5$ was grown in the presence of glucose (Gl), Avicel (Av) and rice straw (RS), and the activities of several lignocellulosic enzymes were determined with chromatometry method. The maximum activities of endoglucanase, exoglucanase, $\beta$-glucosidase, laminarinase, lichenase, xylanase and pectin lyase were $12.52,0.59,2.30,2.37,1.68,15.02$ and $11.40 \mathrm{U} \cdot \mathrm{ml}^{-1}$, respectively. A total of 152, 125 and 61 different proteins were identified in the presence of RS, Av and Gl, respectively, and the proteins were functionally divided into glycoside hydrolases, lipases, peptidases, peroxidases, esterases, protein translocating transporters and hypothetical proteins. A total of 49 proteins were iTRAQ-quantified in all the treatments, and the quantification results indicated that most of the cellulases, hemicellulases and glycoside hydrolases were highly upregulated when rice straw and Avicel were used as carbon sources (compared with glucose).
\end{abstract}

Conclusions: The proteins secreted from A. fumigatus Z5 in the present of different carbon source conditions were identified by LC-MS/MS and quantified by iTRAQ-based quantitative proteomics. The results indicated that $A$. fumigatus Z5 could produce considerable cellulose-, hemicellulose-, pectin- and lignin-degrading enzymes that are valuable for the lignocellulosic bioenergy industry.

Keywords: Lignocellulase, Secretome, Aspergillus fumigatus, LC-MS/MS, iTRAQ

\section{Background}

Concerns regarding the emission of greenhouse gasses, air pollution due to incomplete combustion of fossil fuel, and shortage of fossil fuels have resulted in an increasing focus on alternative energies such as bioethanol, which can be obtained from lignocellulosics [1]. Lignocellulosic waste composed of cellulose, hemicelluloses, and lignin is one of the largest global carbon sources and is thus considered to be a potential feedstock for the production of biofuel [2]. In the future, biofuel from lignocellulosic biomass will be widely used around the world; additionally, the supply of

\footnotetext{
* Correspondence: shenqirong@njau.edu.cn

Jiangsu Key Lab for Organic Solid Waste Utilization, Nanjing Agricultural University, Nanjing 210095, China
}

lignocellulosic biomass from plants or plant-derived materials such as forest and agricultural wastes is inexhaustible [3]. Biofuel is expected to be a renewable resource, and it has the potential to be a major energy source worldwide. However, a large number of cellulosic wastes have been discarded or used inefficiently due to the high cost of utilization processes [4]. Considering these issues, biotransformation has been the subject of intense research in an attempt to develop technologies to convert the abundant quantities of cellulose-rich wastes [5].

The conversion of lignocellulosic biomass into soluble sugars is the primary bottleneck and depends mainly on the production of various efficient lignocellulolytic enzymes [6]. Lignocellulolytic enzymes are a series of enzymes related to lignocellulose degradation, such as cellulases, 
hemicellulases, pectinases, laccase (Lac), manganese peroxidase $(\mathrm{MnP})$ and lignin peroxidase (LiP). Cellulases, composed of endoglucanases (EGs), cellobiohydrolases (CBHs) and $\beta$-glucosidases, are the main enzymes involved in the cellulose degradation process, and they work synergistically to degrade the cellulose fraction [7]. Hemicellulase, produced by a variety of microorganisms during fermentation, is a collective term for a group of enzymes including xylanase, lichenase and laminarinase, which catalyzes the hydrolysis of xylan, lichenin and laminarin, respectively [8]. Pectinase is commonly used in brewing, and pectic enzymes include pectolyase, pectozyme and polygalacturonase. These enzymes break down pectin, a polysaccharide substrate found in plant cell walls [9]. The efficient hydrolysis of lignocellulosic biomass involves the release of long chain polysaccharides and their breakdown into sugars, which requires relayed actions of these enzymes $[2,10]$.

Several strains of fungal and bacterial species are capable of degrading cellulose, hemicellulose and pectin via production of various enzymes and the transport of these enzymes to the outside environment [11]. Aspergillus has gained more attention due to its great capacity for secreting different enzymes related to lignocellulose degradation. Aspergillus niger NS-2 was able to produce appreciable yields of lignocellulolytic enzymes when wheat bran was used as the substrate in solid state fermentation [12], Matkar [10] studied the optimal production of cellulases by Aspergillus sydowii under submerged fermentation. Aspergillus fumigatus Z5 (GenBank accession no. GQ337429.1) was isolated from compost and shown to secrete thermostable cellulases under solid state fermentation as indicated by our preliminary studies [13]. However, most recent research has focused on the isolation of cellulolytic strains, the evaluation of lignocellulolytic enzyme production, and purification of the main components [14-16], but very few studies could be documented on the identification and quantification of the secretome of this species. Comprehensive identification and quantification of the secretomes of cellulolytic strains on different carbon sources can be a useful approach for understanding their special and unique enzyme systems. Additionally, such work may help to unravel the lignocellulose hydrolysis mechanism and determine the industrial application of these strains for bioenergy production $[17,18]$.

Although $A$. fumigatus Z5 owned a good capacity in lignocellulose hydrolysis, it should be noted that $A$. fumigatus was a human pathogen, especially for the immunocompromised patients. In order to discover new enzymes and provide a comparison to other Aspergillus strains (e.g. A. niger) used as industrial hosts, several lignocellulase activities were detected in the liquid medium of $A$. fumigatus $\mathrm{Z} 5$, and its secreted extracellular proteins were identified, quantified and compared by a high-throughput, quantitative, iTRAQ-based LC-MS/MS proteomics approach under glucose, Avicel and rice straw.

\section{Results \\ Determination of various degradative extracellular enzyme activities}

The time courses of various enzymes were determined when glucose, Avicel and rice straw were used as the sole carbon sources, and the results were shown in Figure 1. Endoglucanase activities under the three treatments increased with the incubation time (Figure 1A), and the maximum endoglucanase activity $\left(12.04 \pm 0.22 \mathrm{U} \mathrm{ml}^{-1}\right)$ of RS was obtained on the 4th day. However, the endoglucanase activity in the presence of Gl was maintained at a low level, and its maximum activity was only $0.87 \pm 0.06 \mathrm{U} \mathrm{ml}^{-1}$ on the 3rd day. Changes in exoglucanase activities under different carbon source conditions are shown in Figure 1B. Exoglucanase activities increased gradually in the presence of RS, and the highest value $\left(0.56 \pm 0.03 \mathrm{U} \mathrm{ml}^{-1}\right)$ was obtained at the end of incubation period. The $\beta$-glucosidase activities changed significantly in the presence of Av and RS, and the highest activities were both obtained at 4 days $\left(1.78 \pm 0.16 \mathrm{U} \mathrm{ml}^{-1}\right.$ for Avicel, $2.41 \pm 0.19 \mathrm{U} \mathrm{ml}^{-1}$ for rice straw). The $\beta$-glucosidase activity in the presence of $\mathrm{Gl}$ remained at a lower level until the end of the incubation period (Figure 1C).

The activities of hemicellulases, including laminarinase, lichenase and xylanase, were also determined during the incubation period. In the presence of RS, the laminarinase activities increased gradually and reached $2.03 \pm 0.07 \mathrm{U} \mathrm{ml}^{-1}$ at the end of the incubation period. However, large fluctuations in laminarinase activities were detected in the Av and Gl treatments, and the highest activity in the presence of Av was $1.52 \pm 0.08 \mathrm{U} \mathrm{ml}^{-1}$ obtained at 6 days (Figure 1D). The lichenase activities were shown in Figure 1E. On the first day, the lowest lichenase activity was obtained with $\mathrm{Av}$, and the activity then increased gradually until the end of the incubation period $\left(1.20 \pm 0.11 \mathrm{U} \mathrm{ml}^{-1}\right)$. The lichenase activity peak with RS $\left(1.36 \pm 0.07 \mathrm{U} \mathrm{ml}^{-1}\right)$ was obtained at 7 days. Figure $1 \mathrm{~F}$ shows a time course of xylanase activities. The xylanase activity with RS was $11.04 \pm 0.24 \mathrm{U} \mathrm{ml}^{-1}$ on the first day, and the peak $\left(15.19 \pm 0.28 \mathrm{U} \mathrm{ml}^{-1}\right)$ was reached on the second day, while the xylanase activity in the presence of Av increased gradually, and a peak of $13.10 \pm 0.53 \mathrm{U}$ $\mathrm{ml}^{-1}$ was obtained at 5 days.

The changes in pectin lyase activities during the cultivation period could be described in Figure 1G. The pectin lyase activity increased gradually in the presence of RS, and the highest activity, i e, 11.14 $\pm 0.38 \mathrm{U} \mathrm{ml}^{-1}$ was obtained at the end of the cultivation period. The change in pectin lyase activity in the presence of Av showed the same trend as that observed with RS, but the highest activity was only $5.26 \pm 0.45 \mathrm{U} \mathrm{ml}^{-1}$. The polygalacturonase 


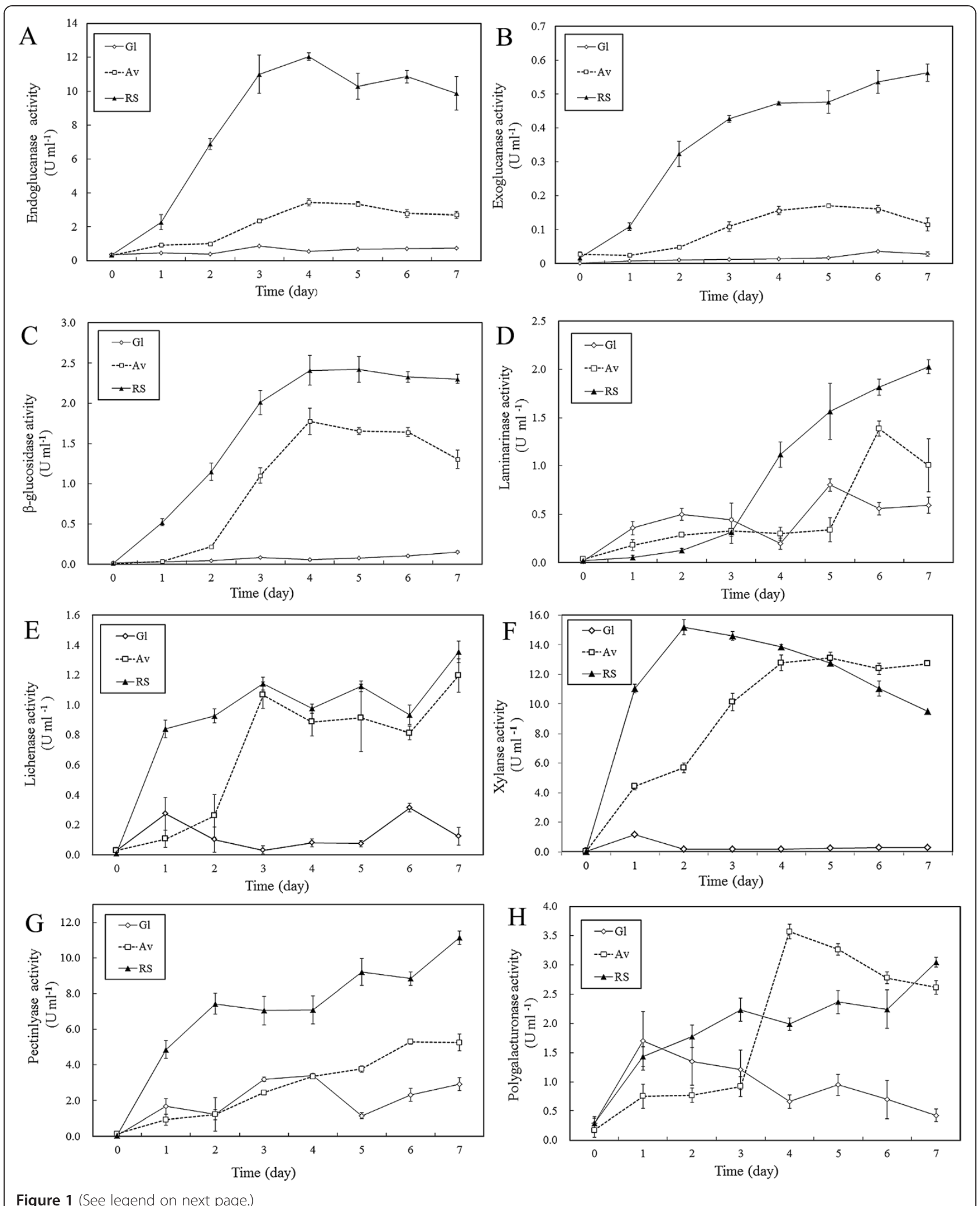

Figure 1 (See legend on next page.) 
(See figure on previous page.)

Figure 1 Activities of extracellular degradative enzymes in the secretome of $A$. fumigatus $Z 5$ in the presence of different carbon sources as determined by spectrophotometric assays. The results are presented as the mean of three replicates, and bars indicate the standard error of three replicates. Time course profiles of cellulase (i.e., endoglucanase, exoglucanase, and $\beta$-glucosidase) production by A. fumigatus Z5 on different carbon sources are shown in $\mathbf{A}, \mathbf{B}$ and $\mathbf{C}$, respectively. Changes in the activities of hemicelluloses such as laminarinase, lichenase, and xylanase as detected by the colorimetric assay are listed in $\mathbf{D}, \mathbf{E}$ and $\mathbf{F}$, respectively; the production of pectinase by A. fumigatus Z5 in the presence of different carbon sources is described in $\mathbf{G}$ and $\mathbf{H}$.

activities were indicated in Figure $1 \mathrm{H}$, and the highest polygalacturonase activity $\left(3.57 \pm 0.12 \mathrm{U} \mathrm{ml}^{-1}\right)$ appeared at 4 days with Av. In the presence of RS, the polygalacturonase activity increased from $0.29 \pm 0.11 \mathrm{U} \mathrm{ml}^{-1}$ to $3.05 \pm 0.09 \mathrm{U} \mathrm{ml}^{-1}$.

In order to comprehensively evaluate the capacity of lignocellulose hydrolysis, ligninolytic enzyme activities (e.g. Lac, $\mathrm{MnP}$ and LiP ) and cellobiose dehydrogenase were also measured, and the results were shown in Additional file 1: Figure S1. However, the ligninolytic enzyme and cellobiose dehydrogenase activities were very low, especially when glucose was used as sole carbon sources, and no ligninolytic enzyme activity could be detected in Gl.

\section{Biomass, protein contents and SDS-PAGE analysis of the supernatants}

Figure 2A presented the growth behavior of A. fumigatus $\mathrm{Z} 5$ on different carbon sources. The cell biomass increased with time and achieved maximum on day 2 in Gl $\left(5.93 \pm 0.38 \mathrm{~g} \mathrm{~L}^{-1} \mathrm{dw}\right)$ and day 4 in RS $\left(5.33 \pm 0.32 \mathrm{~g} \mathrm{~L}^{-1} \mathrm{dw}\right)$,
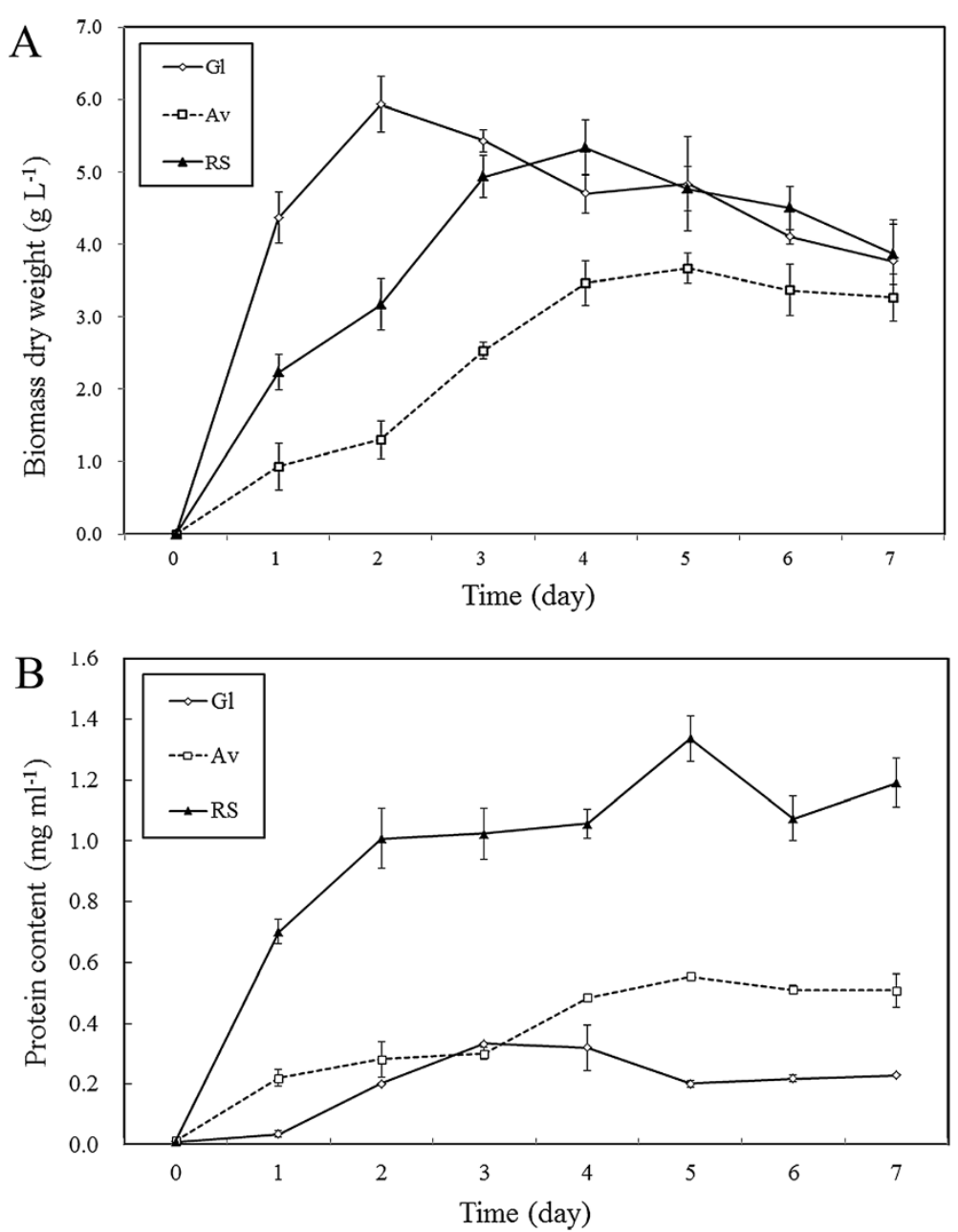

Figure 2 Biomass and protein contents analysis of $A$. fumigatus $\mathbf{Z 5}$ in the present of different carbon sources. (A) Growth of A. fumigatus Z5 induced by different carbon sources. (B) Time course of the protein contents of A. fumigatus Z5 induced by different carbon sources. 
while corresponding days were 5 for $\mathrm{Av}\left(3.67 \pm 0.21 \mathrm{~g} \mathrm{~L}^{-1} \mathrm{dw}\right)$. The data suggested the growth of A. fumigatus Z5 as a function of carbon source. Protein contents in the three treatments were shown in Figure 2B. In the presence of RS, the maximum protein content $\left(1.34 \pm 0.07 \mathrm{mg} \mathrm{ml}^{-1}\right)$ was obtained at the fifth day, after which it decreased to $1.19 \pm 0.09 \mathrm{mg} \mathrm{ml}^{-1}$ at the end of incubation period. The maximum protein content $\left(0.55 \pm 0.01 \mathrm{mg} \mathrm{ml}^{-1}\right)$ was also obtained at the fifth day in the presence of Av. SDS-PAGE analysis of concentrated culture supernatants from different treatments was shown in Figure 3A. Different protein secretomes of A. fumigatus Z5 were found depending on the carbon source, and the protein content of each band was also different. The bands in each lane were selected using Quantity One software, and there were twelve, nineteen and twenty two bands in lane $1(\mathrm{Gl})$, lane $2(\mathrm{Av})$ and lane $3(\mathrm{RS})$, respectively (Figure 3B). The proportion of each band in a given lane could be indicated in Figure 3C, and the bands in row 8 (red frame) were the main components in each lane. The percentage of each band in the corresponding lane were $16.8 \%$ (Gl), $10.5 \%$ (Av) and $8.0 \%(\mathrm{RS})$. In the blue frame, the percentage contents of each band in the corresponding lane were $10.6 \%$ (Av) and $8.1 \%(\mathrm{RS})$.

\section{Zymogram analysis of extracellular degradative enzymes}

The components of the lignocellulose-degrading system of A. fumigatus Z5 induced by different carbon sources were detected by zymogram, and the results were shown in Figure 4. Protein bands were examined based on their ability to hydrolyze CMC incorporated into the gel (Figure 4B). After destaining, 8, 5 and 3 major protein bands that were referred to endoglucanase activity were detected in lanes 1,2 and 3, respectively, and three extra bands presented in the lane of Gl (band c3, e3 and f3). The LC-MS/MS result indicated that glycosyl hydrolase (gi|159121974) was identified in band c3, beta-1,6glucanase (gi|66845136) was observed in band f3, however no relative proteins were identified in band e3. Results of in-gel exoglucanase analysis was shown in Figure 4C. Two fluorescent bands were detected in lanes 1 and 2; while only one fluorescent band was detected in lane 3 , and the LC-MS/MS identification results indicated that cellobiohydrolase (gi|66846140) was in this band. We devised an in-gel activity assay to identify enzymes with $\beta$-glucosidase activity, and the analysis results were shown in Figure 4D. In lane 1 , three bands showed $\beta$-glucosidase activity, and two clear zones were detected in lane 2. However, only one band had the ability to hydrolyze 4-MUG in the Gl lane, and extracellular glycosyl hydrolase/cellulase (gi|66846860) was identified by the LC-MS/MS analysis.

The zymogram analysis of xylanase activity was performed using birchwood xylan as a substrate (Figure 4E). Seven clear zones were obtained in lane 1 , and five clear zones were detected in lane 2. however, only two zones were detected in lane 3. The LC-MS/MS result indicated that no xylanase was identified in band a3 and xylosidase/ glycosyl hydrolase (gi|66846861) was identified in band b3. The in-gel pectinase activities of the supernatants from

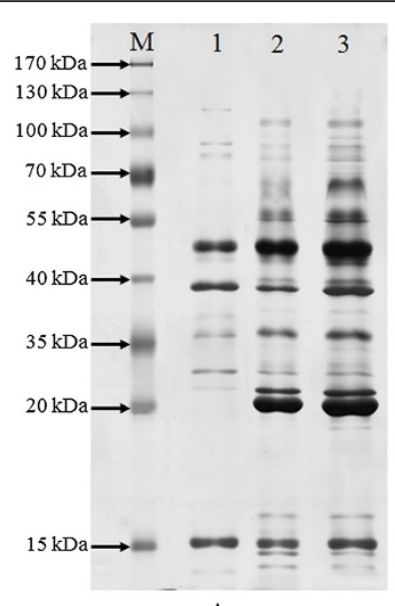

A

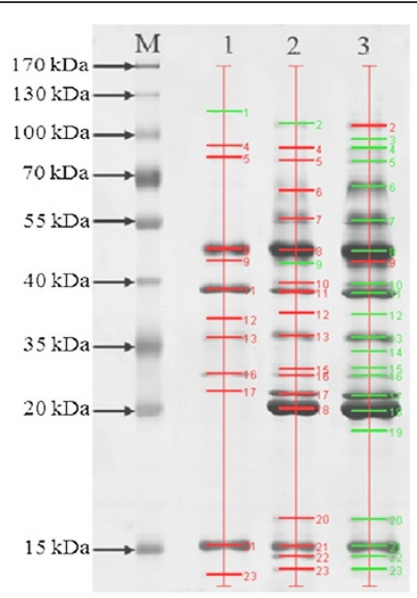

B

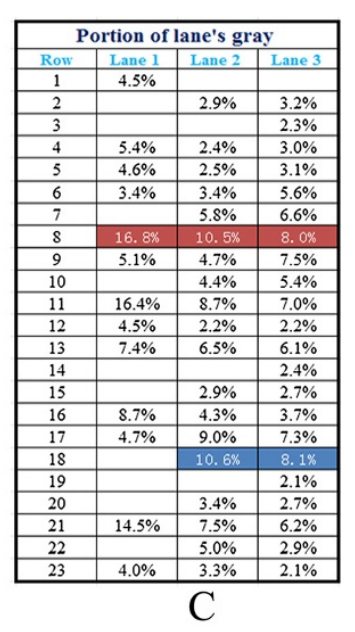

Figure 3 SDS-PAGE and band analysis using Quantity one (A) SDS-PAGE analysis of the secretomes of $A$. fumigatus Z5 induced by different carbon sources. Lane M: molecular weight markers. The sizes $(\mathrm{kDa})$ of the proteins in the prestained molecular mass marker are indicated along the left side. Lane 1: The proteins secreted by A. fumigatus Z5 when glucose was used as the sole carbon source. Lane 2: The proteins secreted by A. fumigatus $Z 5$ when Avicel was used as the sole carbon source. Lane 3: The proteins secreted by A. fumigatus Z5 when rice straw was used as the sole carbon source. (B) The bands in each lane were selected using Quantity one. There were 12, 19 and 22 bands in lane $1(\mathrm{Gl})$, lane $2(\mathrm{Av})$ and lane $3(\mathrm{RS})$, respectively. (C) The proportion of each band in a given lane was calculated and compared across the different treatments. 

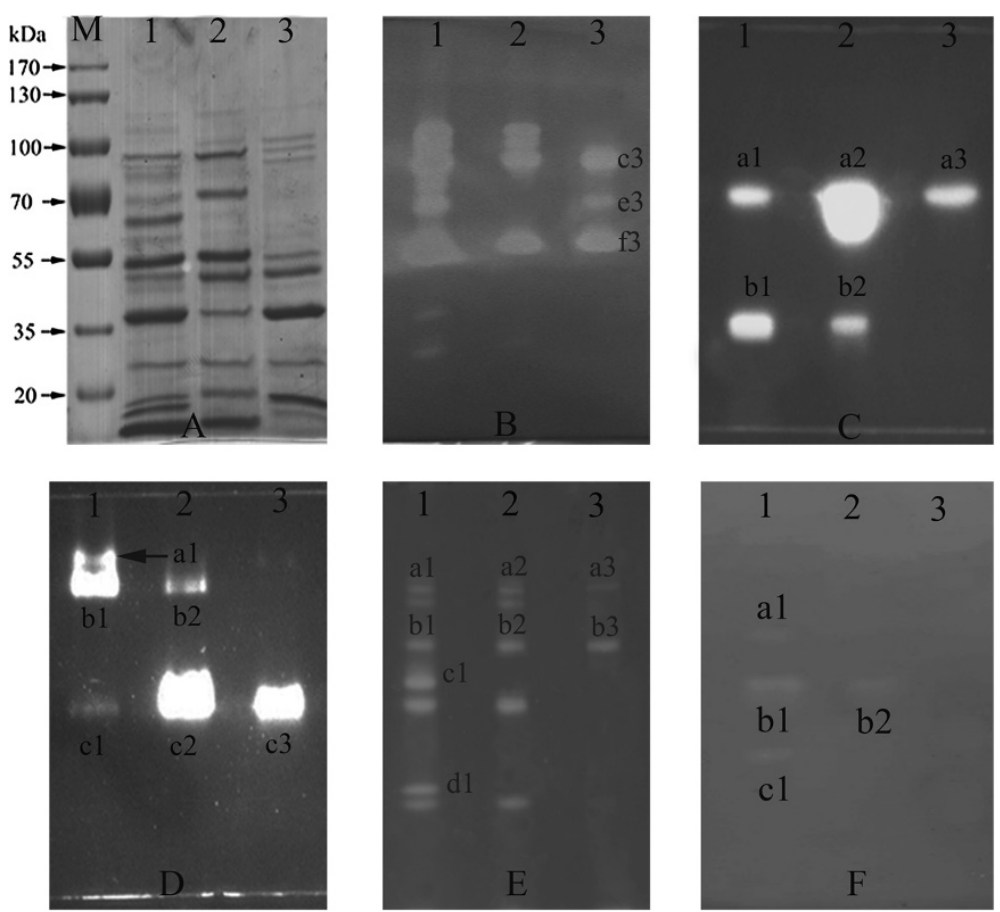

Figure 4 SDS-PAGE (A) and zymogram analysis of cellulase (B, C, D), xylanase (E) and pectinase (F) produced by A. fumigatus Z5. SDS-PAGE was performed with $0.2 \%$ CMC, pNPC, pNPG, xylan and pectin as substrates for endoglucanase, exoglucanase, $\beta$-glucosidase, xylanases and pectinases, respectively. Lane M: molecular weight markers; lane 1: zymogram analysis results of the proteins secreted by A. fumigatus Z5 in the presence of RS; lane 2: zymogram analysis results of the proteins secreted by A. fumigatus Z5 in the presence of Av; lane 3: zymogram analysis results of the proteins secreted by $A$. fumigatus $Z 5$ in the presence of $\mathrm{Gl}$.

different treatments were detected by zymogram analysis, and the results were shown in Figure 4F. In lane 1, three clear zones were detected against the purple background; however, only one zone was detected in lane 2, and no zones were detected in lane 3 .

\section{Identification and quantification of the secretomes from different supernatants}

The proteins that were extracellularly secreted by A. fumigatus Z5 in the presence of different substrates were identified by LC-MS/MS. A total of 221 proteins were identified in the secretome of the different cultures through database searches (NCBInr), out of which thirtyfive were present in all the secretome preparations (Additional file 2). The molecular weights of proteins identified by LC-MS/MS along with an isoelectric point curve were shown in Figure 5. The results suggested that the molecular weights of the proteins were in the range of $10-170 \mathrm{kDa}$, and their isoelectric points ranged between 4.0 and 11.0. The results also indicated that most of the proteins gathered in the acidic side ranging from pI 4-7, which suggested that the secretomes of A. fumigatus Z5 were mainly acidic enzyme. Figure 6A showed a Venn diagram illustrating the number of proteins identified in the different cultures. A total of 152 proteins were identified with RS, 125 proteins were identified with Av, and 61 proteins were identified with Gl. The results also indicated that eighty-six proteins were identified in both RS and Av treatments, and forty-five proteins were found in both Av and Gl treatments. There were 35 proteins were identified in all three treatments, and the details were shown in Additional file 3. These LC-MS/MS-identified proteins were functionally classified according to their biological role. As depicted in Figure 6B, the identified proteins were grouped as cellulose-, hemicellulose-, chitin-, protein-, lipid-, pectin-, or starch-degrading enzymes and oxidordeuctase, dehydrogenase, peptidase or transport proteins. The detailed identification results were shown in Additional file 2.

In this study, we performed a comprehensive analysis of the secretory proteins of $A$. fumigatus Z5 with an iTRAQbased quantitative proteomics approach. The iTRAQquantified proteins were functionally classified, and their roles in lignocellulose hydrolysis were listed in Table 1. All proteins identified in the secretome of A. fumigatus Z5 that were common in all culture conditions were also listed in Additional file 4. To minimize falsely positive results, a strict cutoff for protein identification was applied 


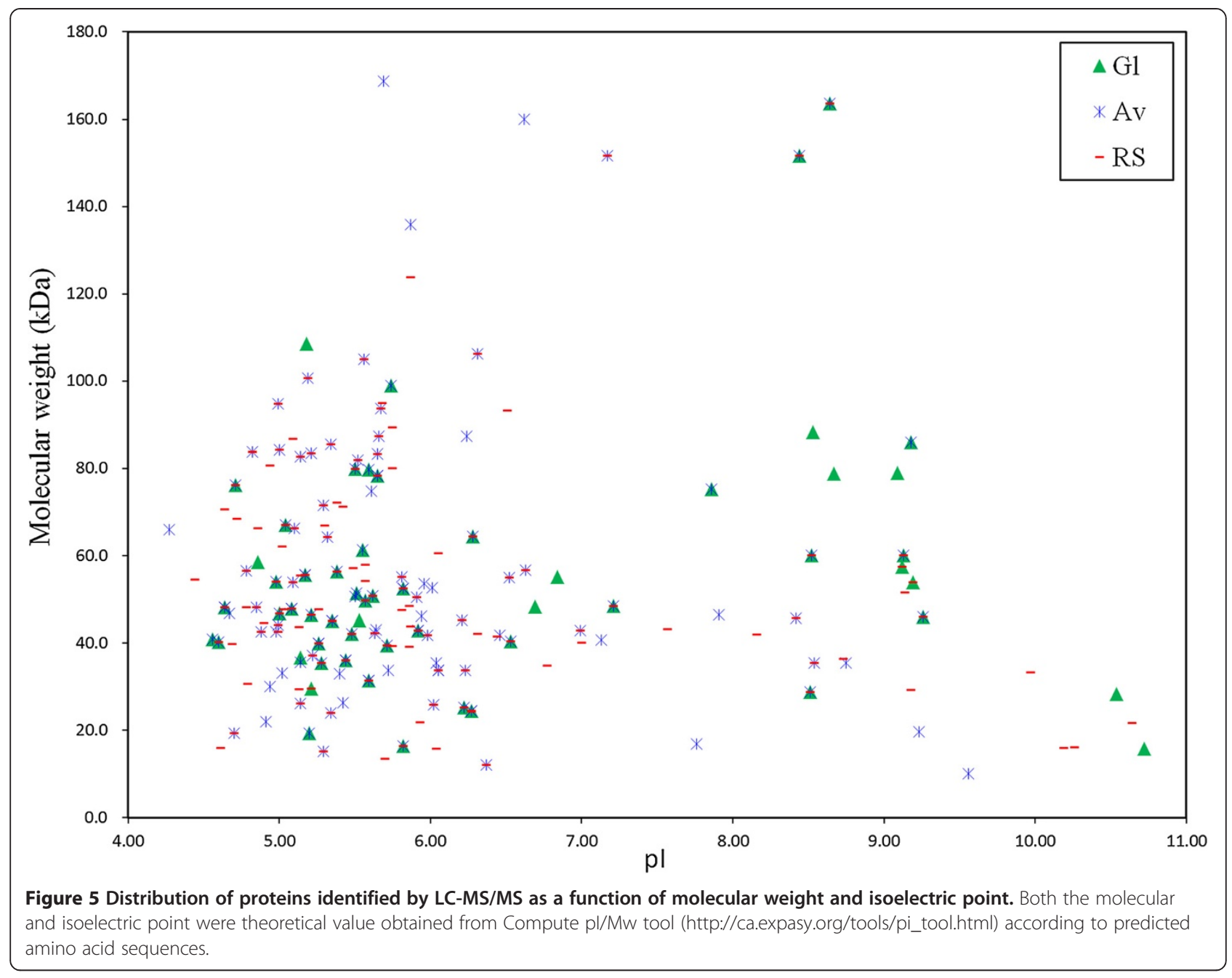

with the unused ProtScore $\geq 1.3$, which corresponded to a confidence limit of $95 \%$.

Although this iTRAQ study quantified many cellulosehydrolyzing enzymes, only fifteen different cellulases and glycosyl hydrolases (including five endoglucanases, three cellobiohydrolases, one $\beta$-glucosidase, and six glycosyl hydrolases) that met the cut-off criterion were quantified in all treatments, and the comparative expression levels of the cellulolytic proteins were presented in Table 1 . When rice straw was used as the sole carbon source, all the identified cellulolytic proteins were upregulated except GH17 $\beta$-1, 3-endoglucanase EglC (gi|66845978); however, $\mathrm{GH} 17$ beta-1 and 3-endoglucanase $\mathrm{EglC}$ were upregulated when A. fumigatus Z5 was cultivated with Avicel compared with their levels under cultivation with glucose. GH61 endo-1,4-beta-glucanase (gi|66846336) and GH12 endoglucanase (gi|66846525) were downregulated when A. fumigatus Z5 was cultivated with Avicel, and the iTRAQ ratios were $0.09 \pm 0.02$ and $0.14 \pm 0.01$, respectively. When rice and Avicel were used as carbon sources, GH2 endoglucanase (gi|66848676) was significantly upregulated with iTRAQ ratios of $0.33 \pm 0.07$ and $0.10 \pm 0.00$, respectively. In this study, when different types of carbon sources were used for cultivation, three cellobiohydrolases were expressed and quantified by iTRAQ. The GH6 cellobiohydrolase (gi|66846140) was identified in the presence of RS, Av and Gl, and the iTRAQ ratios were $0.19 \pm 0.02,0.10 \pm 0.01$, and $0.09 \pm 0.01$, respectively; the GH7 cellobiohydrolase (gi|74670999) was also identified in the presence of RS, Av and Gl, and the iTRAQ ratio of GH7 cellobiohydrolase with RS was 4 times higher than that with Gl; however, it was only 1.5 times higher than that with Avicel. GH7 1,4-beta-D-glucan-cellobiohydrolase (gi|74670557) was also identified and iTRAQ-quantified under all treatments. Only one $\beta$-glucosidase was iTRAQ-quantified in all treatments: the cellobiose-hydrolyzing GH3 $\beta$-glucosidase (gi| 66850743), which was upregulated in both RS and Av, and the $116 / 119$ and $117 / 119$ ratios were 7.00 and 4.33 , respectively. In addition to cellulases, six proteins belong to 


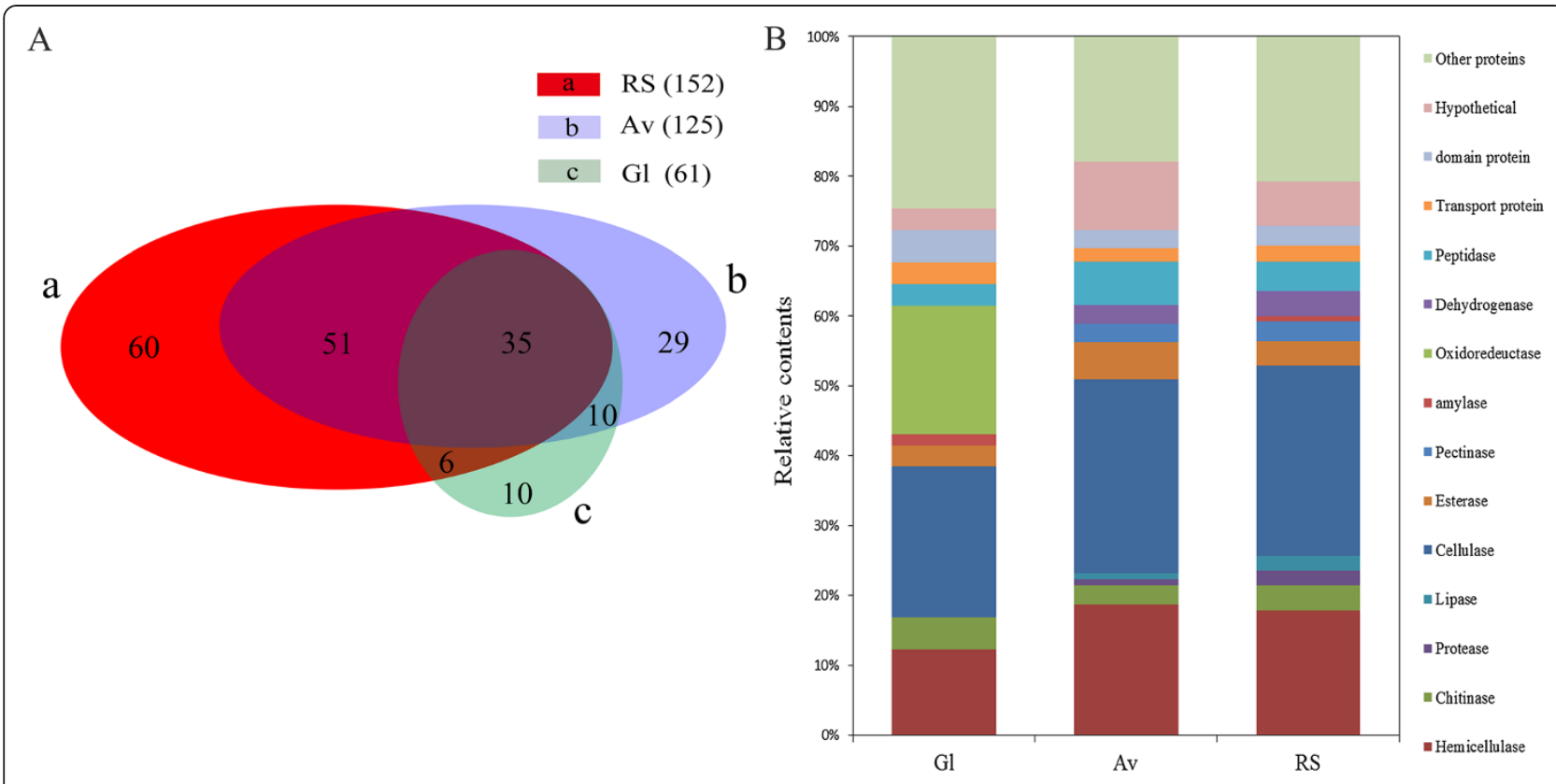

Figure 6 Identification of the secretome of $A$. fumigatus $Z 5$ in the presence of different carbon sources by LC-MS/MS. (A) Venn diagram obtained from the comparison of the A. fumigatus Z5 proteins induced by different carbon sources as identified by LC-MS/MS. Circle a includes the proteins identified in the supernatant of RS, circle $b$ includes the proteins identified in the supernatant of $A v$, and circle $c$ includes the proteins identified in supernatant of $\mathrm{Gl}$. (B) The relative contents of various proteins identified in the different supernatants.

glycoside hydrolase were also iTRAQ-quantified, and the secretion signal analysis results indicated that all of these six proteins had signal peptides.

This study identified and iTRAQ-quantified ten different hemicellulases, including xylanases, xylosidases, mannosidases, arabinases, and galactosidases, under all three treatments. The comparative expression levels of iTRAQ-quantified hemicellulose-degrading proteins could be found in Table 1, and the iTRAQ quantification results showed that the expression levels of all the hemicellulases varied depending on the type of carbon source. In this study, five different endo-1,4-beta-xylanases (gi|66845983, gi|66848870, gi|66851740, gi|70994060, gi|74668470) were iTRAQ-quantified in all treatments, all of which were significantly expressed in the presence of RS relative to Gl. However, compared with their levels in the presence of rice straw, the contents of GH11 xylanase (gi|66845983), GH10 xylanase (gi|66848870) and GH10 xylanase (gi|70994060) were low when Avicel was used for strain culture. GH43 xylosidase (gi|66846861) was significantly produced by $A$. fumigatus Z5 in the presence of RS (0.72) and Av (0.21) when compared to Gl (0.01). GH47 mannosidase MsdS (gi|66850460), which hydrolyzes mannose in substrates, was identified and quantified in all treatments, and the iTRAQ ratio in the presence of RS was $0.44 \pm 0.07$. However, the lowest iTRAQ ratio $(0.06 \pm 0.01)$ was obtained with Av. iTRAQ quantification showed significant upregulation of the hemicellulases, indicating the lignocellulose-hydrolyzing potential of A fumigatus Z5. Of the identified hemicellulases, GH11 alpha-galactosidase (gi|66845449) and GH43 arabinosidase (gi|66846833) lacked secretion signals.

The iTRAQ data demonstrated the secretion of different chitinases by $A$. fumigatus Z5 under different culture conditions, and four different glycosyl hydrolase family 18 chitinases were iTRAQ quantified. The iTRAQ ratio of class V chitinase (gi|129558344) was $0.24 \pm 0.01$ in the presence of RS, which was 2.4 times higher than that observed with $\mathrm{Gl}$, and the quantity of this chitinase was also higher $(0.26 \pm 0.01)$ in the presence of Av compared with Gl. However, another class V chitinase (gi|129556953) showed the opposite result, and the highest iTRAQ ratio $(0.35 \pm 0.07)$ was obtained with $\mathrm{Gl}$.

In addition to cellulases, hemicellulases and chitinases, we additionally quantified several other enzymes via iTRAQ. Pectin depolymerizing pectate lyase (gi|66846844) was also identified in all treatments, and it was significantly upregulated by RS; however, it was downregulated in the presence of Av compared with its level in the presence of Gl. Cellobiose dehydrogenase $(\mathrm{CDH})$ is extracellularly produced by various lignocellulolytic fungi, and it oxidizes the reducing ends of cellobiose and cello-oligosaccharides to their corresponding 1,5-lactones. In this study, one $\mathrm{CDH}$ (gi|66853735) was iTRAQ-quantified in three treatments, and the highest iTRAQ ratio (0.41) was obtained with Av. This ratio was 2.16 times higher than that obtained with $\mathrm{Gl}$. 
Table 1 Functional classification and quantitation of the same proteins identified in different treatments

\begin{tabular}{|c|c|c|c|c|c|c|c|c|c|c|c|c|}
\hline \multirow{2}{*}{$\begin{array}{l}\text { Accession } \\
\text { no. }\end{array}$} & \multirow[t]{2}{*}{ Name of proteins } & \multirow{2}{*}{$\begin{array}{l}\text { LIBER number } \\
\text { peptides }\end{array}$} & \multirow{2}{*}{$\begin{array}{l}\text { num unique } \\
\text { peps }\end{array}$} & \multirow{2}{*}{$\begin{array}{l}\text { tot indep } \\
\text { spectra }\end{array}$} & \multirow{2}{*}{$\begin{array}{l}\text { percent } \\
\text { share of } \\
\text { spectrum id's }\end{array}$} & \multicolumn{3}{|c|}{ iTRAQ Ratio } & \multirow{2}{*}{$\begin{array}{l}116 / \\
119\end{array}$} & \multirow{2}{*}{$\begin{array}{l}117 / \\
119\end{array}$} & \multirow[t]{2}{*}{ Family } & \multirow{2}{*}{$\begin{array}{l}\text { Signal } \\
\text { P }\end{array}$} \\
\hline & & & & & & 116 & 117 & 119 & & & & \\
\hline \multicolumn{13}{|l|}{ Cellulase } \\
\hline gi|66844580 & glycosyl hydrolase family 43 protein & 4 & 1 & 7 & 0.21 & $0.16 \pm 0.03$ & $0.11 \pm 0.01$ & $0.03 \pm 0.01$ & 5.33 & 3.67 & GH 43 (PF04616) & Y \\
\hline gi|66845136 & beta-1,6-glucanase Neg1 & 2 & 1 & 2 & 0.13 & $0.17 \pm 0.02$ & $0.47 \pm 0.02$ & $0.10 \pm 0$ & 1.70 & 4.70 & GH 30 (PF02055) & Y \\
\hline gi|66845978 & beta-1,3-endoglucanase EglC & 25 & 2 & 29 & 1.89 & $0.04 \pm 0.01$ & $0.63 \pm 0.03$ & $0.11 \pm 0.01$ & 0.36 & 5.73 & GH 17 (PF00332) & Y \\
\hline gi|66846140 & cellobiohydrolase & 10 & 1 & 12 & 0.76 & $0.19 \pm 0.02$ & $0.10 \pm 0.01$ & $0.09 \pm 0.01$ & 2.11 & 1.11 & GH 6 (PF01341) & Y \\
\hline gi|66846336 & endo-1,4-beta-glucanase & 10 & 3 & 10 & 0.64 & $0.24 \pm 0.01$ & $0.09 \pm 0.02$ & $0.13 \pm 0.02$ & 1.85 & 0.69 & GH 61 (PF03443) & Y \\
\hline gi|66846525 & endoglucanase & 6 & 2 & 6 & 0.39 & $0.27 \pm 0.03$ & $0.14 \pm 0.01$ & $0.19 \pm 0.04$ & 1.42 & 0.74 & GH 12 (PF01670) & Y \\
\hline gi|66846526 & beta-D-glucoside glucohydrolase & 13 & 2 & 15 & 0.97 & $0.28 \pm 0.01$ & $0.16 \pm 0.01$ & $0.11 \pm 0.01$ & 2.55 & 1.45 & GH 3 (PF00933) & Y \\
\hline gi|66846837 & glucan 1,4-alpha-glucosidase & 3 & 2 & 1 & 0.13 & $0.31 \pm 0.04$ & $0.18 \pm 0.09$ & $0.05 \pm 0.01$ & 6.20 & 3.60 & GH 15 (PF00723) & Y \\
\hline gi|66846860 & extracellular glycosyl hydrolase & 1 & 1 & 1 & 0.09 & $0.17 \pm 0.03$ & $0.15 \pm 0.01$ & $0.07 \pm 0.01$ & 2.43 & 2.14 & GH 62 (PF03664) & Y \\
\hline gi|66848676 & endoglucanase & 2 & 1 & 2 & 0.13 & $0.33 \pm 0.07$ & $0.10 \pm 0$ & $0.03 \pm 0$ & 11.00 & 3.33 & GH 5 (PF00150) & Y \\
\hline gi|66849674 & endoglucanase & 58 & 15 & 109 & 6.98 & $0.31 \pm 0.01$ & $0.12 \pm 0$ & $0.04 \pm 0$ & 7.75 & 3.00 & GH 61 (PM03443) & Y \\
\hline gi|66850620 & extracellular cell wall glucanase & 1 & 1 & 1 & 0.07 & $0.2 \pm 0.04$ & $0.55 \pm 0.07$ & $0.06 \pm 0$ & 3.33 & 9.17 & GH 16 (PF00722) & Y \\
\hline gi|66850743 & beta-glucosidase & 1 & 2 & 1 & 0.15 & $0.42 \pm 0$ & $0.26 \pm 0.02$ & $0.06 \pm 0$ & 7.00 & 4.33 & GH 3 (PF01915) & Y \\
\hline gi|74670557 & 1,4-beta-D-glucan-cellobiohydrolyase & 21 & 12 & 100 & 7.45 & $0.28 \pm 0.01$ & $0.11 \pm 0.01$ & $0.06 \pm 0.01$ & 4.67 & 1.83 & GH 7 (PF00840) & Y \\
\hline gi|74670999 & cellobiohydrolase & 17 & 12 & 35 & 3.22 & $0.30 \pm 0.01$ & $0.09 \pm 0.01$ & $0.06 \pm 0.01$ & 5.00 & 1.50 & GH 7 (PF00840) & Y \\
\hline \multicolumn{13}{|c|}{ Hemicellulase } \\
\hline gi|66845449 & alpha-galactosidase & 2 & 2 & 3 & 0.12 & $0.25 \pm 0.01$ & $0.13 \pm 0.11$ & $0.11 \pm 0.08$ & 2.27 & 1.18 & Melibiase (PF02065) & $\mathrm{N}$ \\
\hline gi|66845983 & endo-1,4-beta-xylanase $(X \ln A)$ & 31 & 9 & 49 & 3.16 & $0.34 \pm 0.01$ & $0.07 \pm 0$ & $0.02 \pm 0.01$ & 17.00 & 3.50 & GH 11 (PF00457) & Y \\
\hline gi|66846833 & arabinosidase & 1 & 2 & 2 & 0.08 & $0.44 \pm 0.09$ & $0.10 \pm 0$ & $0.03 \pm 0$ & 14.67 & 3.33 & GH 43 (PF04616) & N \\
\hline gi|66846861 & xylosidase & 1 & 2 & 4 & 0.20 & $0.72 \pm 0$ & $0.21 \pm 0$ & $0.01 \pm 0$ & 72.00 & 21.00 & GH 43 (PF04616) & Y \\
\hline gi|66848870 & endo-1,4-beta-xylanase & 21 & 7 & 35 & 2.27 & $0.35 \pm 0.01$ & $0.08 \pm 0.01$ & $0.05 \pm 0.01$ & 7.00 & 1.60 & GH 10 ( PF00331 ) & Y \\
\hline gi|66850460 & mannosidase MsdS & 1 & 2 & 6 & 0.09 & $0.44 \pm 0.07$ & $0.06 \pm 0.01$ & $0.13 \pm 0.02$ & 3.38 & 0.46 & GH 47 ( PF01532) & Y \\
\hline gi|66851740 & endo-1,4-beta-xylanase & 2 & 2 & 3 & 0.12 & $0.35 \pm 0.02$ & $0.13 \pm 0.05$ & $0.11 \pm 0.08$ & 3.18 & 1.18 & GH 10 ( PF00331) & Y \\
\hline gi|70981394 & extracellular arabinanase & 4 & 3 & 4 & 0.26 & $0.27 \pm 0.03$ & $0.24 \pm 0.01$ & $0.11 \pm 0.06$ & 2.45 & 2.18 & GH 43 (PF04616) & Y \\
\hline gi|70994060 & extracellular endo-1,4-beta-xylanase & 17 & 10 & 26 & 1.62 & $0.31 \pm 0.01$ & $0.08 \pm 0$ & $0.06 \pm 0.01$ & 5.17 & 1.33 & GH 10 (PF00331) & Y \\
\hline gi|74668470 & endo-1,4-beta-xylanase & 5 & 3 & 5 & 0.23 & $0.28 \pm 0.05$ & $0.24 \pm 0.01$ & $0.13 \pm 0.06$ & 2.15 & 1.85 & GH 11 (PF00457) & Y \\
\hline \multicolumn{13}{|l|}{ Chitinase } \\
\hline gi|129556953 & class $V$ chitinase & 1 & 1 & 1 & 0.09 & $0.27 \pm 0.03$ & $0.10 \pm 0.01$ & $0.35 \pm 0.07$ & 0.77 & 0.29 & GH18 (PF00704) & Y \\
\hline gi|129558344 & class $V$ chitinase & 6 & 8 & 14 & 0.86 & $0.24 \pm 0.01$ & $0.26 \pm 0.01$ & $0.1 \pm 0.02$ & 2.40 & 2.60 & GH 18 (PF00704) & Y \\
\hline gi|66846625 & class III chitinase & 5 & 5 & 5 & 0.30 & $0.19 \pm 0.04$ & $0.17 \pm 0.06$ & $0.15 \pm 0.06$ & 1.27 & 1.13 & GH 18 (PF00704) & Y \\
\hline gil70983075 & class $V$ chitinase $C h i B 1$ & 72 & 23 & 159 & 10.35 & $0.27 \pm 0.01$ & $0.09 \pm 0$ & $0.11 \pm 0.01$ & 2.45 & 0.82 & GH 18 (PF00704) & Y \\
\hline
\end{tabular}


Table 1 Functional classification and quantitation of the same proteins identified in different treatments (Continued)

\begin{tabular}{|c|c|c|c|c|c|c|c|c|c|c|c|c|}
\hline \multicolumn{13}{|c|}{ Phosphatase, lipase, pectinase, lignin degrading proteins, esterase and protease } \\
\hline gi|129557040 & Ser/Thr protein phosphatase family protein & 1 & 2 & 2 & 0.09 & $0.49 \pm 0.08$ & $0.06 \pm 0.01$ & $0.15 \pm 0.02$ & 3.27 & 0.40 & Metallophos (PF00149) & $\mathrm{N}$ \\
\hline gi|129558573 & esterase & 1 & 2 & 3 & 0.18 & $0.07 \pm 0$ & $0.26 \pm 0.02$ & $0.55 \pm 0.05$ & 0.13 & 0.47 & - & Y \\
\hline gi|66845766 & extracellular lipase & 37 & 7 & 64 & 4.12 & $0.07 \pm 0.01$ & $0.34 \pm 0.01$ & $0.35 \pm 0.02$ & 0.20 & 0.97 & Lipase 3 (PF01764) & Y \\
\hline gi|66846844 & pectate lyase & 1 & 1 & 1 & 0.07 & $0.73 \pm 0.04$ & $0.15 \pm 0.01$ & $0.25 \pm 0.04$ & 2.92 & 0.60 & Pec_lyase_C (PF00544) & $\mathrm{Y}$ \\
\hline gi|66849090 & metalloprotease & 10 & 4 & 13 & 0.84 & $0.38 \pm 0.07$ & $0.1 \pm 0.03$ & $0.07 \pm 0.04$ & 5.43 & 1.43 & Peptidase_M35 (MF02102) & $\mathrm{Y}$ \\
\hline gi|66853735 & cellobiose dehydrogenase & 10 & 3 & 12 & 0.79 & $0.16 \pm 0.02$ & $0.41 \pm 0.03$ & $0.19 \pm 0.02$ & 0.84 & 2.16 & GMC_oxred_N (PF00732) & $\mathrm{Y}$ \\
\hline gi|70986104 & CAT1 mycelial catalase Cat1 & 8 & 5 & 10 & 0.60 & $0.21 \pm 0.02$ & $0.09 \pm 0.01$ & $0.25 \pm 0.02$ & 0.84 & 0.36 & Catalase (PF00199) & N \\
\hline gi|70997966 & $\mathrm{Cu}, \mathrm{Zn}$ superoxide dismutase & 4 & 1 & 4 & 0.26 & $0.18 \pm 0.03$ & $0.19 \pm 0.01$ & $0.18 \pm 0.01$ & 1.00 & 1.06 & Sod_Cu (PF00080) & $\mathrm{N}$ \\
\hline \multicolumn{13}{|c|}{ Permease, reductase, helicase and Transporter } \\
\hline gi|66844481 & high affinity methionine permease & 2 & 1 & 2 & 0.13 & $0.28 \pm 0.01$ & $0.19 \pm 0.02$ & $0.17 \pm 0.02$ & 1.65 & 1.12 & AA_permease2 ( PF13520) & N \\
\hline gi|66848496 & thioredoxin reductase GliT & 2 & 4 & 4 & 0.23 & $0.14 \pm 0.08$ & $0.37 \pm 0.06$ & $0.29 \pm 0.01$ & 0.48 & 1.28 & Pyr_redox_2 (PF07992) & $\mathrm{N}$ \\
\hline gi|66848977 & telomere-associated RecQ helicase & 31 & 3 & 52 & 3.16 & $0.01 \pm 0$ & $0.47 \pm 0$ & $0.46 \pm 0.01$ & 0.02 & 1.02 & DUF3505 (PF12013) & N \\
\hline gi|70982865 & MFS transporter & 8 & 3 & 47 & 2.40 & $0.26 \pm 0$ & $0.29 \pm 0.01$ & $0.15 \pm 0$ & 1.73 & 1.93 & MFS_1 (PF07690) & N \\
\hline \multicolumn{13}{|c|}{ Other proteins } \\
\hline gi|129555482 & cytochrome P450 & 5 & 2 & 5 & 0.29 & $0.11 \pm 0.03$ & $0.27 \pm 0.03$ & $0.31 \pm 0.10$ & 0.35 & 0.87 & p450 (PF00067) & N \\
\hline gi|129555486 & secreted antimicrobial peptide & 3 & 2 & 3 & 0.16 & $0.10 \pm 0.04$ & $0.51 \pm 0.09$ & $0.20 \pm 0.01$ & 0.50 & 2.55 & MiAMP1 (PF09117) & Y \\
\hline gi|146324637 & hybrid PKS-NRPS enzyme & 2 & 2 & 3 & 0.13 & $0.18 \pm 0.02$ & $0.16 \pm 0.06$ & $0.32 \pm 0.02$ & 0.56 & 0.50 & Acyl_transf_1 (PF00698) & $\mathrm{N}$ \\
\hline gi|66847207 & HECT domain protein & 5 & 3 & 8 & 0.51 & $0.29 \pm 0.03$ & $0.12 \pm 0.01$ & $0.15 \pm 0.02$ & 1.93 & 0.80 & HECT (PF00632) & N \\
\hline gi|66847547 & C6 finger domain protein & 2 & 1 & 2 & 0.13 & $0.02 \pm 0$ & $0.51 \pm 0$ & $0.39 \pm 0.02$ & 0.05 & 1.31 & Zn_clus (PF00172) & N \\
\hline gi|66851935 & aldose 1-epimerase & 2 & 2 & 13 & 0.11 & $0.26 \pm 0.04$ & $0.16 \pm 0.06$ & $0.32 \pm 0.07$ & 0.81 & 0.50 & Aldose-epim (PF01263) & N \\
\hline gi|66852539 & glutaminase GtaA & 2 & 2 & 3 & 0.18 & $0.40 \pm 0.01$ & $0.03 \pm 0$ & $0.07 \pm 0$ & 5.71 & 0.43 & DUF1793 (PF08760) & Y \\
\hline gi|66853400 & translation initiation factor elF-2B & 49 & 1 & 64 & 3.95 & $0.30 \pm 0$ & $0.27 \pm 0$ & $0.09 \pm 0$ & 3.33 & 3.00 & W2 (PF02020) & $\mathrm{N}$ \\
\hline
\end{tabular}

The peptides from RS, Av and Gl were labeled with the iTRAQ tags 116, 117 and 119, respectively 


\section{Discussion}

Most of the renewable carbon on earth exists in the form of lignocellulose, which is mainly composed of cellulose, hemicelluloses and lignin. Fermentable sugars, which are the hydrolyzed products of lignocellulose, are important substrates for biofuel generation [19]. The hydrolysis of lignocellulose to sugars requires a cocktail of lignocellulolytic enzymes. Microbial cellulase and hemicellulase production is dependent on different carbon sources [20]. In this study, several lignocellulases were detected when glucose, Avicel and rice straw were used as carbon sources, and the results indicated that rice straw was the optimal carbon source for the production of lignocellulases, whereas glucose significantly repressed the production of lignocellulases by A. fumigatus Z5. Dashtban et al. [21] studied the effect of fourteen different carbon sources on cellulase production by Hypocrea jecorina and noted that each strain exhibited minimal cellulase activity when glucose was used as the sole carbon source. In Figure 3A, the Avicel and rice straw lanes had clear new bands at $20 \mathrm{kDa}$, while it disappeared in the Glucose lane. We checked the LC-MS/MS data, and found some relative proteins around $20 \mathrm{kDa}$. These proteins included FG-GAP repeat protein (gi|159130639, pI 5.34, theoretical $\mathrm{Mw}$ 24.07), endo-1,4-beta-xylanase (gi|66845983, pI 6.27, theoretical Mw 24.33), endoglucanase (gi|70986814, pI 6.02, theoretical Mw 25.79), Cu, Zn superoxide dismutase SOD1 (gi|70997966, pI 5.82, theoretical Mw 16.36), putative protein (gi|159128431,pI 4.7, theoretical Mw 19.27), and all these proteins disappeared in the Glucose lane. Endo-1,4-beta-xylanase and endoglucanase belong to glycoside hydrolases family, and they would be inhibited by glucose. Feedback inhibition of lignocellulases by reducing sugars is very common in most of the filamentous fungi. Chulkin et al. [22] studied CreA, which is considered to be a transcriptional regulator of carbon catabolite repression in Penicillium canescens. These authors found that the CreA protein localized to the nucleus irrespective of the nature of the carbon source or the glucose concentration in the medium. ace1 was also a repressor of cellulase and xylanase. Nina Aro et al. [23] characterized the effect of a deletion of the ace 1 gene in Trichoderma reesei, and they found that deletion of acel caused an increase in the expression of all the main cellulase and xylanase genes.

Lignocellulases, especially cellulases and hemicellulases, play major roles during the biodegradation of lignocellulosic biomass, which is considered to be an abundant renewable resource. The production of lignocellulases is the main bottleneck during bioenergy production. In this study, all types of enzymes exhibited maximal activity when rice straw was used as a carbon source. Hideno et al. [24] noted that the choice of carbon source was an important factor in the production of cellulases and hemicellulases. Rice straw has gained considerable interest because of its high annual production (731 million tons), which can be potentially transformed into approximately 205 billion liters of bio-ethanol per year [25]. Rice straw may be suitable for the production of cellulase and hemicellulase due to its physical and chemical characteristics, and cellulose (41\%) and hemicellulose (20\%) are the main components in rice straw [14].

Hiroki et al. [26] used zymography to detect endoglucanase and xylanase activities. In this study, endoglucanase, exoglucanase, $\beta$-glucosidase, xylanase, and pectinase were detected in the gel, and the results revealed that rice straw was a suitable carbon source for the production of lignocellulases by A. fumigatus Z5. This finding was consistent with previous studies [27,28]. Asiya et al. [27] reported the differential expression of endoglucanase and $\beta$-glucosidase isoforms in Aspergillus terreus cultivated with different carbon sources. These authors found that the maximum $\beta$-glucosidase activity $\left(28.0{\mathrm{U} \cdot \mathrm{g}^{-1}}^{-1}\right)$ and the greatest number of bands were obtained when rice straw was used as the carbon source.

The biodegradation of various types of lignocellulosic biomass into reducing sugars requires a wide range of enzymes including cellulases, hemicellulases, pectinases, peroxidases, and others [29]. The complete transformation of cellulose into sugar requires a series of enzymes including endoglucanases randomly cleaving the cellulose chain, exoglucanases attacking the chain ends, and $\beta$ glucosidases catalyzing the hydrolysis of cellobiose into glucose. The efficient hydrolysis of lignocellulosic biomass depends on the appropriate expression of endoglucanase, exoglucanase and $\beta$-glucosidase [30], which work synergistically to degrade the cellulose fraction. Thus, a lack (or low expression level) of any of these enzymes would affect the hydrolysis of lignocellulose biomass. Trichoderma reesei was considered to be a potential producer of endoglucanases, cellobiohydrolase and $\beta$-glucosidase [19]; however, low $\beta$-glucosidase activity limited further application of T. reesei. Although Aspergillus niger has the potential to produce all the cellulase components with high $\beta$-glucosidase activity, its cellulose hydrolysis efficiency was limited due to a low level of endoglucanase expression [31]. The main advantages of the A. fumigatus Z5 cellulase system were its thermostable characteristics and broad $\mathrm{pH}$ range; however, the enzyme activity determination results indicated that its cellobiohydrolase activity $\left(0.59 \mathrm{U} \cdot \mathrm{ml}^{-1}\right)$ was low, which would limit its application in cellulose degradation. Co-culturing with a strain which has high levels of cellobiohydrolase is likely to be an effective method for improving cellulose hydrolysis efficiency [32].

In this study, the iTRAQ quantification results with RS showed significant upregulation of all the quantified hemicellulases, indicating the lignocellulosic degradation potential of A. fumigatus Z5. However, there was no 
significant upregulation of the quantified hemicellulases in the presence of Av, which might be due to the characteristics of the substrate. Hemicelluloses embedded in the cell wall of rice straw act as bridges that connect pectin to cellulose, forming cross-linked fibers [29]. Celluloses and pectins are easily accessible to cellulases and pectinase only when hemicelluloses are hydrolyzed by hemicellulases [33]. Therefore, hemicellulases play an important role in the degradation of lignocellulosic biomass. Hemicellulases are enzymes that degrade hemicellulose polymers, and these enzymes include endo-1, 4 - $\beta$-xylanase, $R$-glucuronidase, $\beta$-xylosidase, acetylxylan esterase and R-L-arabinofuranosidase [29]. Pectin is a complex heteropolymer of homogalacturonan, which can be converted into reducing sugars and subsequently fermented into bioethanol [34]. Pectin can be hydrolyzed by pectate lyase, which is responsible for the eliminative cleavage of pectate [35]. In this study, three and four pectate lyases were identified by LC-MS/MS in the presence of $\mathrm{Av}$ and Rs, respectively, while none were identified with Gl. Manavalan et al. [36] revealed that most pectinases can be induced by cellulose. However, the iTRAQ results showed that pectate lyase A (gi) 66846844) was detected in all treatments, thus revealing that pectate lyase $\mathrm{A}$ is a constitutively expressed enzyme. On the other hand, these results indicate that iTRAQ technology is more accurate and sensitive than common LC-MS/MS.

\section{Conclusions}

The evaluation of various lignocellulase activities and zymogram analysis results indicated that A. fumigatus Z5 has great potential for use in the bioenergy industry, and the production of various microbial cellulases and hemicellulases was dependent on the carbon source. Proteomics is a very effective technique for understanding the mechanism by which different lignocellulolytic enzymes are secreted by A. fumigatus Z5. The cultivation of A. fumigatus Z5 with different lignocellulosic substrates (rice straw and Avicel) highlighted the differential expression levels of lignocellulolytic enzymes including cellulases, hemicellulases, glycoside hydrolases, chitinases, esterases, peptidases, lipases, protein translocating transporters and hypothetical proteins.

\section{Experimental procedures}

\section{Strain growth conditions and protein extraction}

The lignocellulosic decomposing strain A. fumigatus $\mathrm{Z} 5$ was isolated from the compost and identified as previously reported [13]. The strain was grown on potato dextrose agar (PDA) medium conidia production, and then conidia were harvest by washing the plate with 10 $\mathrm{ml}$ sterile $\mathrm{dd}_{2} \mathrm{O}$, after removing of the mycelia, the conidia were re-suspended and adjusted the concentration to $1 \times 10^{6}$ conidia $\mathrm{ml}^{-1} .1 \%(\mathrm{v} / \mathrm{v}, \mathrm{ml}$ suspension per $\mathrm{ml}$ liquid medium) fresh conidia suspension of strain Z5 was inoculated into nine separate test flasks (1L) containing Mandels' salts solution [37] supplemented with $1 \%(\mathrm{w} / \mathrm{v})$ different carbon sources (rice straw, Avicel and glucose), and all the test flasks were incubated at $50^{\circ} \mathrm{C}$ and $170 \mathrm{rpm}$. After 7 days of incubation, the substrates and fungal biomass were removed by centrifugation $\left(10,000 \mathrm{~g}\right.$ for $10 \mathrm{~min}$ at $\left.4^{\circ} \mathrm{C}\right)$ and further clarified by filtration through a $0.45 \mu \mathrm{m}$ membrane (Beyotime, China). The clear supernatant was used as the crude enzyme extract in the subsequent experiments. The fungal biomass was collected by filtrated through two layers of gauze, and then washed by $\mathrm{ddH}_{2} \mathrm{O}$ for three times. The dry weights of different samples were obtained by determination the constant weight at $105^{\circ} \mathrm{C}$. The proteins in the clear supernatant were concentrated by lyophilization and redissolved in acetate buffer (50 mM, pH 5.0).

\section{Enzyme assays}

Endoglucanase (EG) activity was estimated by the DNS method [38] with glucose as a standard. Substrate solution for the EG assays consisted of 1\% CMC (Sigma, USA) in sodium acetate buffer ( $50 \mathrm{mM}, \mathrm{pH} 5.0) .0 .1 \mathrm{ml}$ crude enzyme was mixed with $2 \mathrm{ml}$ substrate solution and $2.9 \mathrm{ml}$ distilled water, and incubated for $20 \mathrm{~min}$ at $50^{\circ} \mathrm{C}$. One unit of enzyme activity was defined as the amount of enzyme required to release $1 \mu \mathrm{mol}$ of reducing sugars in $1 \mathrm{~min}$. Cellobiohydrolase (CBH) activity and $\beta$-glucosidase activity were measured by a microtiter plate method using the chromogenic substrates $\beta$-nitrophenyl- $\beta$-D-cellobioside (pNPC) (Sigma, USA) [39] and $\beta$-nitrophenyl- $\beta$-D-glucopyranoside (pNPG) (Sigma, USA) [40], respectively. $10 \mu \mathrm{l}$ crude enzyme was mixed with $25 \mu \mathrm{l}$ of $200 \mathrm{mM}$ sodium acetate buffer $(\mathrm{pH}$ 5.0), $25 \mu \mathrm{l} 10 \mathrm{mM}$ substrate and $40 \mu \mathrm{l}$ of distilled water. The plate was incubated at $50^{\circ} \mathrm{C}$ for $10 \mathrm{~min}$, the reaction was terminated by adding $100 \mu \mathrm{l} 1 \mathrm{M} \mathrm{Na} \mathrm{Na}_{3}$ and the colour developed was read at $405 \mathrm{~nm}$. One unit of enzyme activity was defined as the amount of enzyme required to release $1 \mu \mathrm{mol}$ of pNP per minute under the above assay conditions.

Activities of the hemicellulose enzymes, including laminarinase (endo- $\beta-1,3$-glucanase), lichenase (endo- $\beta$ 1,$3 ; 1,4$-glucanase), and xylanase (endo- $\beta$-1,4-xylanase and 1,4- $\beta$-D-xylan xylanohydrolase), were measured according to Linton et al. [8], and laminarin (Aladdin Chemistry Co. Ltd, Cat. No. 9008-22-4), lichenin (Megazyme, Bry, Ireland) and xylan (from birchwood; Sigma, CAS: 9014-63-5) were used as substrates, respectively. $10 \mu \mathrm{l}$ crude enzyme was incubated with 100 $\mu \mathrm{l} 1 \%(\mathrm{w} / \mathrm{v})$ substrate and $90 \mathrm{ml}$ of $0.1 \mathrm{~mol} \mathrm{~L}^{-1} \mathrm{Na}$ acetate 
buffer ( $\mathrm{pH} \mathrm{5.5)} \mathrm{at} 50^{\circ} \mathrm{C}$ for $10 \mathrm{~min}$, and the reaction was stopped with $50 \mathrm{ml}$ of $0.3 \mathrm{~mol} \mathrm{~L}^{-1} \mathrm{HCl}$ and the mixture was then neutralized with $10 \mathrm{ml}$ of $2.5 \mathrm{~mol} \mathrm{~L}^{-1} \mathrm{~K}_{2} \mathrm{CO}_{3}$. One unit of enzyme activity was defined as the amount of enzyme required to release $1 \mu \mathrm{mol}$ of reducing sugars from the substrate in $1 \mathrm{~min}$.

Pectin lyase activity was determined by monitoring the increase in absorbance at $235 \mathrm{~nm}$ according to Delgado et al. [41]. The reaction mixture contained $1.0 \mathrm{ml}$ of $1.0 \%$ pectin, $1.0 \mathrm{ml}$ of $0.05 \mathrm{M}$ Tris-acetate buffer $(\mathrm{pH}$ 8.8 ) and $0.5 \mathrm{ml}$ culture filtrate and was incubated at $40^{\circ}$ $\mathrm{C}$ for $20 \mathrm{~min}$. One $0.5-\mathrm{ml}$ aliquot was taken from the reaction mixture and added to a test tube containing 4.5 $\mathrm{ml}$ of $0.01 \mathrm{M} \mathrm{HC1}$ to stop the reaction. One unit of pectin lyase activity was defined as the amount of enzyme that produced an increase in absorbance of 0.1 at 235 $\mathrm{nm}$ in the reaction mixture under the assay conditions. The assay of polygalacturonase activity was followed Pathak and Sanwal [42]. The assay reagents contained $0.2 \mathrm{ml}$ of $0.2 \mathrm{M}$ acetate buffer $(\mathrm{pH} 4.5), 0.3$ $\mathrm{ml}$ of $1 \%$ polygalacturonic acid in $0.05 \mathrm{M}$ acetate buffer solution ( $\mathrm{pH} 4.5)$ and $0.5 \mathrm{ml}$ crude enzyme, and this reaction system was incubated for $20 \mathrm{~min}$ at $40^{\circ} \mathrm{C}$. One unit of polygalacturonase was defined by the catalyzation of the hydrolytic cleavage to form $1 \mu \mathrm{M}$ of galacturonic acid in 1 min under standard conditions.

\section{Protein assay, SDS-PAGE and zymogram analysis}

Protein content was quantified in the supernatants using a Micro BCA protein assay kit (Beyotime, China) according to the manufacturer's protocol. The developed color was read at $562 \mathrm{~nm}$ using a Multi-Detection Microplate Reader (Spectra max M5, Molecular Devices, Sunnyvale, CA), and bovine serum albumin (BSA) was used as the standard. SDS-PAGE was performed using a $10 \%(\mathrm{w} / \mathrm{v})$ polyacrylamide gel as described by Laemmli [43]. Based on the protein concentration, 40 $\mu \mathrm{l}$ supernatants (RS:47.5 $\mu \mathrm{g}$, Av: $21.0 \mu \mathrm{g}, \mathrm{Gl}: 12.8 \mu \mathrm{g}$ ) from each treatment were loaded on the gel. After destaining, the gel was analyzed using Quantity one (Bio-Rad).

Zymogram analysis of endoglucanase was performed by adding CMC to the gel [44]. Detection of the in-gel $\beta$-glucosidase activity was performed according to Kim et al. [45] with some modifications. After renaturation, the gels were washed with distilled water and subsequently overlaid with $0.5 \mathrm{mM} 4$-methylumbelliferyl $\beta$-Dglucopyranoside (Sigma, USA) in $0.1 \mathrm{M}$ succinate buffer $(\mathrm{pH}$ 5.8), and the presence of a fluorescent reaction product was determined under UV light $(365 \mathrm{~nm})$ after incubating the gels at $50^{\circ} \mathrm{C}$ for $5 \mathrm{~min}$. Detection of the in-gel exoglucanase activity performed similarly to that of $\beta$-glucosidase activity, but the substrate was 4methylumbelliferyl- $\beta$-D-cellobioside (Sigma, USA).
Zymogram analysis of xylanase was performed by the method of Tseng et al. [46]. Approximately $10 \mu \mathrm{g}$ of each sample was subjected to SDS-PAGE using a gel containing $0.5 \%$ xylan. After renaturation, the gel was stained with a $0.1 \%(\mathrm{w} / \mathrm{v})$ Congo red solution for $30 \mathrm{~min}$ before destaining with $1 \mathrm{M} \mathrm{NaCl}$. In-gel pectinase activity was detected following the method of Schneider et al. [47]. $0.1 \%$ pectin was incorporated into the gel, and the proteins were renatured after electrophoresis. The gels containing pectin were stained with $0.05 \%$ ruthenium red for $10 \mathrm{~min}$ and subsequently washed with water until colorless bands could be detected against a purple background.

\section{SDS-PAGE (1D) coupled to LC-MS/MS}

Protein digestion and peptide extraction were performed according to Liu et al. [48] with some modifications. After SDS-PAGE analysis, the bands sliced from different lanes were washed with $\mathrm{ddH}_{2} \mathrm{O}$ twice and de-stained at room temperature with de-staining solution $(25 \mathrm{mM}$ $\mathrm{NH}_{4} \mathrm{HCO}_{3}, 50 \% \mathrm{ACN}$ ) for $30 \mathrm{~min}$, and then kept in dehydration solution 1 (50\% ACN) for $30 \mathrm{~min}$. The bands were treated with reduction solution $1 \quad(25 \mathrm{mM}$ $\mathrm{NH}_{4} \mathrm{HCO}_{3}, 1 \mathrm{mM}$ DTT) at $57^{\circ} \mathrm{C}$ for $1 \mathrm{~h}$ after washing by dehydration solution $2(100 \% \mathrm{ACN})$ for $30 \mathrm{~min}$, and then transferred to reduction solution $2(25 \mathrm{mM}$ $\mathrm{NH}_{4} \mathrm{HCO}_{3}, 50 \mathrm{mM}$ IAA) and kept at room temperature for $30 \mathrm{~min}$. The imbibition solution $\left(25 \mathrm{mM} \mathrm{NH}_{4} \mathrm{HCO}_{3}\right)$ was added after remove the reduction solution 2. After that, the gels were treated with dehydration solution 1 and dehydration solution 2 each for $30 \mathrm{~min}$ in order. The gels were rehydrated in $10 \mu \mathrm{l}$ digest solution $(0.02$ ug $\mathrm{ul}^{-1}$ trypsin in cover solution) for $30 \mathrm{~min}$, and $20 \mu \mathrm{l}$ cover solution ( $\left.25 \mathrm{mM} \mathrm{NH}_{4} \mathrm{HCO}_{3}, 10 \% \mathrm{CAN}\right)$ was added for digestion 16 hours at $37^{\circ} \mathrm{C}$. The supernatants were transferred into another tube. The gels were extracted once with $50 \mu \mathrm{l}$ extraction buffer (5\% TFA、67\%ACN) at $37^{\circ} \mathrm{C}$ for $30 \mathrm{~min}$. The peptide extracts and the gel supernatant were combined and then completely dried. Mass spectrometric analysis was carried out as follows: The samples were resuspended with redissolved solution, and chromatography was performed using an Eksigent nanoLC-Ultra ${ }^{\text {Tu }}$ 2D System (AB SCIEX). The samples were loaded on an in-house packed trap column (100 $\mu \mathrm{m} \times 3 \mathrm{~cm}, \mathrm{C} 18,3 \mu \mathrm{m} 150 \AA$ ) and washed for $10 \mathrm{~min}$ at $4 \mu \mathrm{l} \mathrm{min}{ }^{-1}$. Subsequently, an elution gradient of $5-35 \%$ acetonitrile $(0.1 \%$ formic acid) over 70 min was run with an in-house packed analytical column $(75 \mu \mathrm{m} \times 15 \mathrm{~cm}$, $\mathrm{C} 18,3 \mu \mathrm{m} 150 \AA$ ) with a spray tip. Data acquisition was performed with a TripleTOF 5600 System (AB SCIEX), and the data were acquired using an ion spray voltage of $2.5 \mathrm{kV}$. The MS was operated with TOF-MS scans. For IDA, survey scans were acquired in $250 \mathrm{~ms}$. The data were processed with ProteinPilot software v. 4.0 (AB SCIEX). 
The tolerances were specified as $\pm 0.05 \mathrm{Da}$ for peptides and $\pm 0.05 \mathrm{Da}$ for MS/MS fragments. False discovery rate (FDR) analysis was also performed using the integrated tools in ProteinPilot.

\section{iTRAQ labeling and automated 2D LC-MS/MS protein identification}

One gram solid secretome powder of A. fumigatus Z5

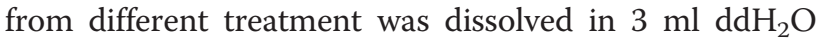
and concentrated by running through an Amicon YM-3 centrifugal filter unit with a 3-kDa molecular mass cutoff membrane filter (Millipore, Bedford, MA). After quantified by BCA method, $50 \mu \mathrm{g}$ (RS), $22.1 \mu \mathrm{g}$ (Av) and $13.5 \mu \mathrm{g}(\mathrm{Gl})$ proteins were used for protein digestion and iTRAQ labeling. The protein digestion was performed following the method of Riviere et al. [49]. iTRAQ labeling was carried out in accordance with Adav et al. [50,51], and the peptide samples were labeled using the iTRAQ Reagent Multiplex Kit (Applied Bio systems, Foster City, CA) according to the manufacturer's protocol. The samples from RS, Av and Gl substrates were labeled with the iTRAQ tags 116,117 and 119 , respectively.

Automated 2D LC-MS/MS analysis was carried out according to Liu et al. [48] with some modifications. The labeled peptides were desalted through a C18 solid phase extraction column (Waters Corporation, Milford, USA) and subsequently dried using a vacuum centrifuge. All the extracted peptides were resuspended in loading buffer ( $5 \mathrm{mM}$ ammonium formate containing $5 \%$ acetonitrile, $\mathrm{pH}$ 3.0). The collected samples were separated and analyzed on the 2D-nano LC/MS system. The LTQ Orbitrap XL mass spectrometer (Thermo Electron Corp.) was operated in the data-dependent mode to switch automatically between MS and MS/MS acquisition [52]. During MS/MS, the activating parameters of the precursor ions were $40 \%$ normalized collision energy and an activation time of $30 \mathrm{~ms}$. The relative abundance of the peptides and proteins in different samples were reflected by the peak intensities of the three iTRAQ reporter ions.

Protein identification and quantification for the iTRAQ experiments were performed with ProteinPilot software (version 4.0; Applied Biosystems, USA). The database used for searching was the A. fumigatus Af293 NCBI database (with 19983 entries). The Paragon Algorithm in ProteinPilot was used for peptide identification and isoform-specific quantification. The data search parameters were set up as follows: Trypsin (KR) cleavage with two missed cleavage sites was considered along with fixed modification of cysteines by methyl methanethiosulfonate (MMTS). iTRAQ modification of peptide/protein identification and quantification was also performed with the ProteinPilot software version
4.0. The database and data search parameters were the same as above. iTRAQ modification of lysine residues, peptide $\mathrm{N}$ termini, and methionine oxidation were set as variable modifications. A strict cutoff for protein identification was applied with an unused ProtScore $\geq 1.3$, which corresponds to a confidence limit of $95 \%$, to minimize false positive results. At least two peptides with 95\% confidence were considered for protein quantification. The resulting data set was auto bias-corrected to eliminate any variation due to unequal mixing when combining different labeled samples. For iTRAQ quantitation, the peptide used for quantification was automatically selected by the Pro Group algorithm (at least two peptides with $99 \%$ confidence) to calculate the reporter peak area, error factor $(\mathrm{EF})$, and $\mathrm{p}$-value. $\mathrm{N}$ termini, methionine oxidation and ITRAQ modification of lysine residues were set as variable modifications. To minimize false positive results, a strict cut off for protein identification was applied with an unused ProtScore $\geq 1.3$, which corresponds to a confidence limit of $95 \%$, and at least two peptides with 95\% confidence were considered for protein quantification. The resulting data set was auto bias-corrected to eliminate any variation due to unequal mixing when combining different labeled samples. For iTRAQ quantitation, the peptide used for quantification was automatically selected by the Pro Group algorithm (at least two peptides with 99\% confidence) to calculate the reporter peak area, error factor $(\mathrm{EF})$, and $\mathrm{p}$-value. The existence of signal peptide sequences was determined using the signal peptide prediction program SignalP, version 4.1 (http://www.cbs. dtu.dk/services/SignalP/).

\section{Additional files}

\footnotetext{
Additional file 1: Figure S1. Ligninolytic enzyme and cellobiose dehydrogenase activities in the secretome of A. fumigatus Z5 in the presence of different carbon sources. The results are presented as the mean of three replicates, and bars indicate the standard error of three replicates. Time course profiles of ligninolytic enzymes (i.e., laccase, manganese peroxidase and lignin peroxidase) production by $A$. fumigatus $\mathrm{Z} 5$ on different carbon sources are shown in $A, B$ and $C$, respectively. The production of cellobiose dehydrogenase $(\mathrm{CDH})$ by $A$. fumigatus $Z 5$ in the presence of different carbon sources is described in D.

Additional file 2: The LC-MS/MS identification results.

Additional file 3: Table S1. The set of 35 proteins common identified in all three treatments i.e. RS, Av and Gl.

Additional file 4: The iTRAQ quantification results.
}

\section{Abbreviations}

EG: Endoglucanase; CBH: Cellobiohydrolase; pNPC: $\beta$-nitrophenyl- $\beta-D-$ cellobioside; pNPG: $\beta$-nitrophenyl- $\beta$-D-glucopyranoside; 4-MUG:

4-methylumbelliferyl $\beta$-D-glucopyranoside; 4-MUC: 4-methylumbelliferyl- $\beta$-Dcellobioside.

\section{Competing interests}

The authors declare that they have no competing interests. 


\section{Authors' contributions}

DL performed the majority of the experiments and wrote the manuscript. JL extracted the secretomes. MW and YM performed the LC-MS/MS experiments and data analyses. YS determined the lignocellulase activities, and SZ performed the zymography analyses. RZ assisted in the drafting and revision of the manuscript. QS was the corresponding author, and he supervised the work and contributed to the manuscript. All authors have read the manuscript and approved the submission to this journal.

\section{Acknowledgments}

This work was financially supported by National Natural Science Foundation of China for Youth (31201685), the Chinese Ministry of Science and Technology (2011CB100503), and the Agricultural Ministry of China (201103004)

Received: 10 June 2013 Accepted: 1 October 2013

Published: 16 October 2013

\section{References}

1. Zaldivar J, Nielsen J, Olsson L: Fuel ethanol production from lignocellulose: a challenge for metabolic engineering and process integration. Applied microbiology and biotechnology 2001, 56:17-34.

2. Adav SS, Ng CS, Arulmani M, Sze SK: Quantitative iTRAQ secretome analysis of cellulolytic Thermobifida fusca. Journal of proteome research 2010, 9:3016-3024.

3. Kumar R, Singh S, Singh OV: Bioconversion of lignocellulosic biomass: biochemical and molecular perspectives. Journal of industrial microbiology \& biotechnology 2008, 35:377-391.

4. Cheol KK, Yoo S-S, Y-A OH, Seong-Jun K: Isolation and characteristics of Trichoderma harzianum FJ1 producing cellulases and xylanase. Journal of microbiology and biotechnology 2003, 13:1-8.

5. Ding S-j, Ge W, Buswell JA: Secretion, purification and characterisation of a recombinant Volvariella volvacea endoglucanase expressed in the yeast Pichia pastoris. Enzyme Microb Technol 2002, 31:621-626.

6. Manavalan A, Adav SS, Sze SK: iTRAQ-based quantitative secretome analysis of Phanerochaete chrysosporium. Journal of proteomics 2011, 75:642-654.

7. Krogh K, Kastberg H, Jørgensen C, Berlin A, Harris P, Olsson L: Cloning of a GH5 endoglucanase from genus Penicillium and its binding to different lignins. Enzyme Microb Technol 2009, 44:359-367.

8. Linton SM, Greenaway P: Presence and properties of cellulase and hemicellulase enzymes of the gecarcinid land crabs Gecarcoidea natalis and Discoplax hirtipes. Journal of experimental biology 2004, 207:4095-4104.

9. Patil SR, Dayanand A: Production of pectinase from deseeded sunflower head by Aspergillus niger in submerged and solid-state conditions. Bioresource technology 2006, 97:2054-2058.

10. Kumar P, Barrett DM, Delwiche MJ, Stroeve P: Methods for pretreatment of lignocellulosic biomass for efficient hydrolysis and biofuel production. Ind Eng Chem Res 2009, 48:3713-3729.

11. Aro N, Pakula T, Penttilä M: Transcriptional regulation of plant cell wall degradation by filamentous fungi. FEMS microbiology reviews 2005 , 29:719-739.

12. Bansal N, Tewari R, Soni R, Soni SK: Production of cellulases from Aspergillus niger NS-2 in solid state fermentation on agricultural and kitchen waste residues. Waste management 2012, 32:1341-1346.

13. Liu D, Zhang R, Yang X, Wu H, Xu D, Tang Z, Shen Q: Thermostable cellulase production of Aspergillus fumigatus $\mathrm{Z} 5$ under solid-state fermentation and its application in degradation of agricultural wastes. Int Biodeter Biodegr 2011, 65:717-725.

14. Narra M, Dixit G, Divecha J, Madamwar D, Shah AR: Production of cellulases by solid state fermentation with Aspergillus terreus and enzymatic hydrolysis of mild alkali-treated rice straw. Bioresour Technol 2012, 121:355-361.

15. Cunha F, Esperança M, Zangirolami T, Badino A, Farinas C: Sequential solid-state and submerged cultivation of Aspergillus niger on sugarcane bagasse for the production of cellulase. Bioresour Technol 2012, 112:270-274.

16. Herculano PN, Porto TS, Maciel MH, Moreira KA, Souza-Motta CM, Porto AL Partitioning and purification of the cellulolytic complex produced by Aspergillus japonicus URM5620 using PEG-citrate in an aqueous twophase system. Fluid Phase Equilib 2012, 335:8-13.
17. Kuhad RC, Gupta R, Singh A: Microbial cellulases and their industrial applications. Enzyme Research 2011, 2011:10.

18. Herpoel-Gimbert I, Margeot A, Dolla A, Jan G, Molle D, Lignon S, Mathis H, Sigoillot J-C, Monot F, Asther M: Comparative secretome analyses of two Trichoderma reesei RUT-C30 and CL847 hypersecretory strains. Biotechnology for Biofuels 2008, 1:18.

19. Juhasz T, Szengyel Z, Reczey K, Siika-Aho M, Viikari L: Characterization of cellulases and hemicellulases produced by Trichoderma reesei on various carbon sources. Process Biochem 2005, 40:3519-3525.

20. Jun $H$, Kieselbach $T$, Jönsson $L$ : Enzyme production by filamentous fungi: analysis of the secretome of Trichoderma reesei grown on unconventional carbon source. Microb Cell Fact 2011, 10:68.

21. Mehdi Dashtban RB, Wensheng Q: Effect of different carbon sources on cellulase production by Hypocrea jecorina (Trichoderma reesei) strains. Int J Biochem Mol Biol 2011, 2:274-286.

22. Chulkin AM, Vavilova EA, Benevolenskii SV: Transcriptional regulator of carbon catabolite repression CreA in filamentous fungus. Mol Biol (Mosk) 2010, 44:677-687.

23. Aro N, IImén M, Saloheimo A, Penttilä M: ACEl of Trichoderma reesei is a repressor of cellulase and xylanase expression. Applied and environmental microbiology 2003, 69:56-65.

24. Hideno A, Inoue H, Tsukahara K, Yano S, Fang X, Endo T, Sawayama S: Production and characterization of cellulases and hemicellulases by Acremonium cellulolyticus using rice straw subjected to various pretreatments as the carbon source. Enzyme Microb Technol 2011, 48:162-168.

25. Balat $\mathrm{M}$, Balat $\mathrm{H}, \mathrm{Oz} \mathrm{C}$ : Progress in bioethanol processing. Prog Energy Combust Sci 2008, 34:551-573.

26. Matsui H, Ban-Tokuda T: Studies on carboxymethyl cellulase and xylanase activities of anaerobic fungal isolate CR4 from the bovine rumen. Curr Microbiol 2008, 57:615-619.

27. Nazir A, Soni R, Saini HS, Kaur A, Chadha BS: Profiling differential expression of cellulases and metabolite footprints in Aspergillus terreus. Appl Biochem Biotechnol 2010, 162:538-547.

28. Wang T-Y, Chen H-L, Lu M, Chen Y-C, Sung H-M, Mao C-T, Cho H-Y, Ke H-M, Hwa T-Y, Ruan S-K: Functional characterization of cellulases identified from the cow rumen fungus Neocallimastix patriciarum W5 by transcriptomic and secretomic analyses. Biotechnol Biofuels 2011, 4:24.

29. Adav SS, Li AA, Manavalan A, Punt P, Sze SK: Quantitative iTRAQ secretome analysis of aspergillus niger reveals novel hydrolytic enzymes. J Proteome Res 2010, 9:3932-3940.

30. Kumar RS S, Singh OV: Bioconversion of lignocellulosic biomass: biochemical and molecular perspectives. I Indust Microbiol Biotechnol 2008, 35:377-391.

31. Maheshwari DKG S, Paul J, Verma A: A paper mill sludge as a potential source for cellulose production by Trichoderma reesei QM9123 and Aspergillus niger using mixed cultivation. Carbohydr Polym 1994, 23:161-163.

32. Madamwar D, Patel S: Formation of cellulases by co-culturing of Trichoderma reesei and Aspergillus niger on cellulosic waste. World J Microbiol Biotechnol 1992, 8:183-186.

33. Saha BC: Alpha-L-arabinofuranosidases-biochemistry, molecular biology and application in biotechnology. Biotech Adv 2000, 18:403-423.

34. Carpita NCG DM: Structural models of primary cell walls in flowering plants: consistency of molecular structure with the physical properties of the walls during growth. Plant J 1993, 3:1-30.

35. Wing RA, Yamaguchi J, Larabell SK, Ursin VM, McCormick S: Molecular and genetic characterization of two pollen-expressed genes that have sequence similarity to pectate lyases of the plant pathogen Erwinia. Plant Mol Biol 1990, 14:17-28.

36. Arulmani Manavalan SSA, Siu Kwan S: iTRAQ-based quantitative secretome analysis of Phanerochaete chrysosporium. Journal of proteomics 2011, 75:642-654.

37. Mandels M, Weber J: The production of cellulases. Am Chem Soc 1969, 95:391-414.

38. Miller GL: Use of dinitrosalicylic acid reagent for determination of reducing sugar. Analytical chemistry 1959, 31:426-428.

39. Lahjouji K, Storms R, Xiao Z, Joung K-B, Zheng Y, Powlowski J, Tsang A, Varin $\mathrm{L}$ : Biochemical and molecular characterization of a cellobiohydrolase from trametes versicolor. Applied microbiology and biotechnology 2007, 75:337-346. 
40. Parry NJ, Beever DE, Owen E, Vandenberghe I, Van Beeumen J, Bhat MK: Biochemical characterization and mechanism of action of a thermostable beta-glucosidase purified from thermoascus aurantiacus. Biochem J 2001, 353:117.

41. Delgado L, Trejo BA, Huitrón C, Aguilar G: Ectin lyase from aspergillus sp. CH-Y-1043. Applied microbiology and biotechnology 1993, 39:515-519.

42. Pathak N, Sanwal G: Multiple forms of polygalacturonase from banana fruits. Phytochemistry 1998, 48:249-255.

43. Laemmli UK: Cleavage of structural proteins during the assembly of the head of bacteriophage T4. Nature 1970, 227:680-685.

44. Holt SM, Hartman PA: A zymogram method to detect endoglucanases from Bacillus subtilis, Myrothecium verrucaria and Trichoderma reesei. J Ind Microbiol Biotechnol 1994, 13:2-4.

45. Kim KH, Brown KM, Harris PV, Langston JA, Cherry JR: A proteomics strategy to discover $\beta$-glucosidases from Aspergillus fumigatus with two-dimensional page in-gel activity assay and tandem mass spectrometry. Journal of proteome research 2007, 6:4749-4757.

46. Tseng M-J, Yap M-N, Ratanakhanokchai K, Kyu KL, Chen S-T: Purification and characterization of two cellulase free xylanases from an alkaliphilic Bacillus firmus. Enzyme Microb Technol 2002, 30:590-595.

47. Schneider T, Gerrits B, Gassmann R, Schmid E, Gessner MO, Richter A, Battin $\mathrm{T}$, Eberl $\mathrm{L}$, Riedel $\mathrm{K}$ : Proteome analysis of fungal and bacterial involvement in leaf litter decomposition. Proteomics 2010, 10:1819-1830.

48. Liu Y, Wu J, Yan G, Hou R, Zhuang D, Chen L, Pang Q, Zhu J: Proteomic analysis of prolactinoma cells by immuno-laser capture microdissection combined with online two-dimensional nano-scale liquid chromatography/mass spectrometry. Proteome Sci 2010, 8:2

49. Riviere $L R$, Tempst $P$ : Enzymatic digestion of proteins in solution. Curr Protoc Protein Sci 2001, 11:1-9.

50. Adav SS, Ng CS, Sze SK: iTRAQ-based quantitative proteomic analysis of Thermobifida fusca reveals metabolic pathways of cellulose utilization. J Proteomics 2011, 74:2112-2122.

51. Adav SS, Ravindran A, Sze SK: Quantitative proteomic analysis of lignocellulolytic enzymes by Phanerochaete chrysosporium on different lignocellulosic biomass. J Proteomics 2012, 75:1493-1504.

52. Sun H, Li M, Gong L, Liu M, Ding F, Gu X: iTRAQ-coupled 2D LC-MS/MS analysis on differentially expressed proteins in denervated tibialis anterior muscle of Rattus norvegicus. Mol Cell Biochem 2012, 364:193-207.

doi:10.1186/1754-6834-6-149

Cite this article as: Liu et al:: Secretome diversity and quantitative analysis of cellulolytic Aspergillus fumigatus $\mathrm{Z} 5$ in the presence of different carbon sources. Biotechnology for Biofuels 2013 6:149.

\section{Submit your next manuscript to BioMed Central and take full advantage of:}

- Convenient online submission

- Thorough peer review

- No space constraints or color figure charges

- Immediate publication on acceptance

- Inclusion in PubMed, CAS, Scopus and Google Scholar

- Research which is freely available for redistribution 